\title{
Preparation of Non-polluting Tb-Doped Mesoporous Carbon Nitride Photocatalyst and Study on the Efficacy and Mechanism of Degradation of Antibiotics in Water
}

\author{
Bing Wang \\ Northeast Electric Power University \\ Qingtong Cao \\ Northeast Electric Power University \\ Guomin Li ( $\sim 20202995 @$ neepu.edu.cn ) \\ Northeast Electric Power University \\ Jian Zhang \\ Northeast Electric Power University
}

\section{Research Article}

Keywords: g-C3N4, Photocatalysis, Rare earth elements, Mesoporous structures, Safety assessment, Chlorophyll.

Posted Date: September 28th, 2021

DOI: https://doi.org/10.21203/rs.3.rs-906252/v1

License: (c) (1) This work is licensed under a Creative Commons Attribution 4.0 International License. Read Full License 


\section{Abstract}

Given that the biological treatment of antibiotic wastewater can easily induce resistant bacteria, the photocatalytic degradation of antibiotics is considered a better method for treating antibiotic wastewater. Therefore, the ability to remove Tylosin (TYL) and Tetracycline (TC) in aqueous solution using rare earth element Tb-doped g- $\mathrm{C}_{3} \mathrm{~N}_{4}$ under simulated natural solar radiation was investigated. A series of rare earth $\mathrm{Tb}^{3+}$ doped mesoporous g- $\mathrm{C}_{3} \mathrm{~N}_{4}$ were successfully prepared by nitric acid treatment and $\mathrm{Tb}\left(\mathrm{NO}_{3}\right)_{3} \cdot 5 \mathrm{H}_{2} \mathrm{O}$ samples showed significantly higher degradation efficiency for TYL and TC than pure g- $\mathrm{C}_{3} \mathrm{~N}_{4}$. Leaching toxicity experiments were carried out on the catalyst using chard seeds and demonstrated negligible toxicity of the leachate from the catalyst. The structure, elemental state, optical properties, morphology and photogenerated carrier separation of the prepared XTCN catalysts were characterized by XRD, XPS, UV-Vis DRS, TEM and PL. The results showed that Tb doping enhanced the photocatalytic activity of the g- $\mathrm{C}_{3} \mathrm{~N}_{4}$ catalyst by narrowing the band gap while improving the light-trapping ability; The separation and transport rate of photogenerated carriers were significantly increased after Tb doping. Finally, a simple, efficient and non-polluting Tb-doped carbon nitride photocatalyst is successfully developed in this paper.

\section{Introduction}

With the rapid growth of the pharmaceutical industry, the production and use of antibiotics for humans and animals is increasing (Gao 2018; Wang 2020). Although antibiotics can cure many diseases in a timely manner, large amounts of antibiotic wastewater are increasingly discharged. Because of its high organic content,deep colour,the presence of a variety of inhibiting bacteria and the difficulty of biodegradation, the wastewater is one of the most widespread environmental pollution,which seriously threatens the ecological environment and human health. For example, tetracycline antibiotics (TC) used in large-scale livestock, poultry and aquaculture have characteristic of good antibacterial activity and inexpensiveness, making them one of the most widely used antibiotic classes (Briones 2016; Hu 2011). However, the structural specificity of antibiotics makes it difficult for residual TC to degrade naturally in the natural environment, and in addition antibiotics inhibit or disrupt microbial growth, so the rate of biodegradation of most TC is much lower than the rate of abiotic degradation. Thus there is an urgent need to develop more efficient and greener technologies for pharmaceutical wastewater treatment in order to meet the higher requirements for water safety (Hu 2011; Karageorgou 2014; Wen 2018; Zhang 2015).

Currently, due to the outstanding advantages of easy operation, high catalytic efficiency and low preparation cost, photocatalytic technology has shown great potential in water purification compared with traditional water treatment technology, so how to improve the photocatalytic degradation efficiency has become a research hotspot (Amandeep 2016; Wan Kuen 2018).Compared to other common semiconductor materials, $\mathrm{g}-\mathrm{C}_{3} \mathrm{~N}_{4}$ is a metal-free material for organic polymer semiconductors and has the advantages of low production cost, stable physicochemical properties, environmental friendliness, suitable forbidden band width and visible photocatalytic activity (F. Wang 2018; Fu 2019; Ma 2019; Yan 
2009), as well as showing efficient photocatalytic activity in the degradation of TC (Wang 2018), which is of wide interest to photocatalytic researchers. Nonetheless, for practical applications in energy and environmental photocatalysis, $\mathrm{g}-\mathrm{C}_{3} \mathrm{~N}_{4}$ still suffers from some unavoidable problems, such as fast photogenerated electron-hole complexation, low quantum efficiency and poor visible light absorption, which limit its photocatalytic activity in water decomposition (Li 2017; Wang 2018; Yan 2019). Currently, various types of co-catalysts such as $\mathrm{Ag}, \mathrm{Mn}, \mathrm{Fe}, \mathrm{Bi}, \mathrm{Cu}$ and $\mathrm{Co}$ and their compounds are doped in $\mathrm{g}-\mathrm{C}_{3} \mathrm{~N}_{4}$ to increase photocatalytic activity (Chen 2009; Ding 2010; Faisal 2016; Jiang 2017; Wang 2017). Among the metallic elements, the incomplete occupation of $4 \mathrm{f}$ and empty $5 \mathrm{~d}$ orbitals by rare earth elements allows them not only to act as centres for electron capture, but also to increase the light absorption capacity and in the case of photocatalysts,to greatly increase their photoelectric activity (Cerrato 2018; Gao 2018; Zhang 2018). In addition, rare earth ions can use $4 \mathrm{f}$ orbitals to interact with a variety of organic functional groups and thus form complexes with a variety of Lewis bases (organic acids, aldehydes, alcohols and thiols), which can better aggregate organic matter onto the photocatalyst surface and thus improve photocatalytic degradation efficiency (Tang 2013). At the same time rare earth elements are also a traditionally important upconversion luminescent material, but their application in photocatalysis is less reported (Sun 2015; Vignesh 2017; Zhu 2019; Zou 2018). Xu et al. doped Eu into g$\mathrm{C}_{3} \mathrm{~N}_{4}$ for the degradation of methylene blue, and the Eu/g- $\mathrm{C}_{3} \mathrm{~N}_{4}$ catalyst showed well photocatalytic activity in the experiment ( $\mathrm{Xu}$ 2013). Li et al. prepared new catalysts by doping Er and Sm into $\mathrm{g}-\mathrm{C}_{3} \mathrm{~N}_{4}$ by direct thermal polymerization and characterized that the doping of Er and Sm changed the electronic and chemical properties of $\mathrm{g}-\mathrm{C}_{3} \mathrm{~N}_{4}$ and weakened the fluorescence emission intensity, thus enhancing the photocatalytic activity of $\mathrm{g}-\mathrm{C}_{3} \mathrm{~N}_{4}$ ( $\mathrm{Li} 2020 ; \mathrm{Li} 2020$ ). As a rare-earth element, it also possesses the properties of rare-earth elements, incompletely occupying as well as empty electron orbitals.

Recently, the impact of nanomaterials on the environment is also receiving increasing attention due to their special physical and chemical properties. Photocatalysts based on $\mathrm{g}-\mathrm{C}_{3} \mathrm{~N}_{4}$ as a common nanomaterial are environmentally friendly and free of secondary pollution. Nevertheless, the toxicity of rare-earth doped g- $\mathrm{C}_{3} \mathrm{~N}_{4}$ has been relatively little studied; Degradation of contaminants in water is one of the main roles of photocatalysts and therefore the leaching toxicity of the catalyst samples in aqueous solution needs to be determined. No team has yet studied the effects of leaching solutions of rare earth doped g- $\mathrm{C}_{3} \mathrm{~N}_{4}$ on plant growth and on physiology. The germination rate and rhizome length of plant seeds are important growth indicators that reflect the growth state of the plant. When plant seeds are under suitable conditions, they absorb water and swell to germinate and enzymatic activity is enhanced. If the leaching solution is toxic, it will inactivate the enzymes and inhibit seed germination, disrupting the germination process and thus affecting the germination potential and germination rate of the seeds (Mazumder 2020). Plant chlorophyll is an important substance for photosynthesis by absorbing solar energy, and the level of chlorophyll in plant leaves is one of the most important physiological indicators of plant growth and development (Mishra 2009; Mobin 2007; Tripathi 2015).

In the present work, the photocatalytic degradation experiments of antibiotics by g- $\mathrm{C}_{3} \mathrm{~N}_{4}$ doped with a small amount of $\mathrm{Tb}^{3+}$ ions under simulated solar radiation were investigated. We will prepare new porous 
nanophotocatalysts by doping terbium into $\mathrm{g}-\mathrm{C}_{3} \mathrm{~N}_{4}$ and protonating it with nitric acid and acting as a gas soft template. Meanwhile, the effects of terbium ion doping concentration on morphology, structure and photocatalytic activity are investigated in detail. The stability and recoverability of the samples were evaluated by repeated experiments of photocatalytic degradation of. The leaching toxicity of xTCN samples were evaluated by germination and growth experiments on cabbage seedlings, and growth indicators (seed germination and rhizome length) and physiological indicators (chlorophyll). In addition, a possible mechanism for the $0.01 \mathrm{TCN}$ catalyst to improve the photocatalytic degradation efficiency was proposed.

\section{Materials And Methods}

\subsection{Materials and reagents}

Melamine (99\%), $\mathrm{Tb}\left(\mathrm{NO}_{3}\right)_{3} \cdot 5 \mathrm{H}_{2} \mathrm{O}(99.9 \%), \mathrm{TYL}(\geq 800 \mathrm{units} / \mathrm{mg})$ and TC $(98 \%)$ were purchased from Aladdin Co. Nitric acid (AR) was obtained from Yaohua chemical reagent co. LTD (Tianjin,China). All materials don't require further purification and all water used throughout the experiments is deionised water. Cabbage seeds purchased from Farmers' Market.

\subsection{Preparation of photocatalyst}

To begin with, dissolve an appropriate amount of $\mathrm{Tb}\left(\mathrm{NO}_{3}\right)_{3} \cdot 5 \mathrm{H}_{2} \mathrm{O}$ in $7.5 \mathrm{~mL}$ of dilute nitric acid $\left(\mathrm{HNO}_{3}\right)$, add $2 \mathrm{~g}$ of melamine after the sample has completely dissolved and mix well. After drying, the mixture is transferred to a semi-closed crucible with a lid and subsequently heated to $200^{\circ} \mathrm{C}$ at a rate of $5^{\circ} \mathrm{C} / \mathrm{min}$ and then held for $2 \mathrm{~h}$, then continued to $550^{\circ} \mathrm{C}$ and held for $2 \mathrm{~h}$. After cooling, the prepared pale yellow fluffy sample was removed and ground well in an agate mortar and pestle. Depending on the molar percentage of $\mathrm{Tb}\left(\mathrm{NO}_{3}\right)_{3} \cdot 5 \mathrm{H}_{2} \mathrm{O}$ added to the prepared samples $(0.005 \%, 0.01 \%, 0.02 \%)$, they were named $0.005 \mathrm{TCN}, 0.01 \mathrm{TCN}$ and $0.02 \mathrm{TCN}$ respectively. The product yield of XTCN is very stable and unaffected by the addition of $\mathrm{Tb}\left(\mathrm{NO}_{3}\right)_{3} \cdot 5 \mathrm{H}_{2} \mathrm{O}$. Nitric acid treated g- $\mathrm{C}_{3} \mathrm{~N}_{4}$ polymers, labelled $\mathrm{HCN}$, were prepared under the same conditions without the addition of $\mathrm{Tb}\left(\mathrm{NO}_{3}\right)_{3} \cdot 5 \mathrm{H}_{2} \mathrm{O}$.

Pure $\mathrm{g}-\mathrm{C}_{3} \mathrm{~N}_{4}$ was prepared according to previous reports. Briefly, $2 \mathrm{~g}$ of melamine powder was added to a semi-closed crucible and covered. The crucible was then placed in a muffle and heated to $550^{\circ} \mathrm{C}$ in air at a rate of $5^{\circ} \mathrm{C}$ per minute. After cooling to room temperature, the sample was removed and ground to a fine powder, noted as $\mathrm{CN}$.

\subsection{Characterization}

The prepared catalysts were analyzed in crystalline phase using x-ray diffraction (XRD, RigakuD/migaku) of CuKa rays $(\lambda=1.5406 \AA)$. XRD was performed with an operating current of $50 \mathrm{~mA}$ and an accelerating voltage of $40 \mathrm{KV}$. Chemical bonding in samples using Fourier transform infrared spectroscopy (FT-IR, Shimabu FT-IR8900, with potassium bromide as reference) in the range of $400-4000 \mathrm{~cm}^{-1}$. The UV diffuse reflectance spectrum of the catalyst was obtained using a UV-2550 spectrophotometer (Shimazu) 
equipped with an integrated sphere using $100 \%$ barium sulfate as the reflected light sample. The surface properties of the photocatalysts were studied by $x$-ray photoelectron spectroscopy (XPS, ESCALAB 250Xi, ThermoFisher). The morphology and structure of the prepared samples were characterized using transmission electron microscopy(TEM, JEOL 2100, JEOL Ltd). The samples were characterized by photoluminescence $(\mathrm{PL})$ using a steady-state transient fluorescence spectrometer with an excitation wavelength of $300 \mathrm{~nm}$.

\subsection{Evaluation of photocatalytic activity}

The photocatalytic activity of the Tb-doped g- $\mathrm{C}_{3} \mathrm{~N}_{4}$ catalyst was investigated using TYL and TC as representative antibiotics for degradation. For the experiments carried out simulating solar radiation, a 170W xenon lamp was used. During photocatalytic degradation, $30 \mathrm{mg}$ of the prepared samples were added to $60 \mathrm{ml}$ of TYL solution ( $25 \mathrm{mg} / \mathrm{L})$ or TC $(25 \mathrm{mg} / \mathrm{L})$, respectively. The prepared mixture is then magnetically stirred under continuous exposure to simulated solar irradiation. The photocatalytic reaction mixture is removed periodically for a certain period of light exposure. The obtained mixed solution was centrifuged at $8000 \mathrm{rmp}$ for 5 minutes. The concentrations of TYL and TC in the centrifuged solutions were measured using a UV spectrophotometer at visible luminosity wavelengths of $290 \mathrm{~nm}$ and $357 \mathrm{~nm}$ respectively. For the reusability of $0.01 \mathrm{TCN}$ for antibiotic removal, repeat durability experiments were conducted for antibiotic degradation degradation. After each cycle of the experiment, the TCN was centrifuged, then washed with deionised water and anhydrous ethanol,dried at $60^{\circ} \mathrm{C}$ and then used for the next cycle of the experiment.

\subsection{Leaching process and toxicity tests}

Photocatalysts have excellent results in degrading wastewater, so we should investigate the leaching toxicity of photocatalysts. $25 \mathrm{mg}$ of catalyst was added to $50 \mathrm{~mL}$ of deionised water, stirred continuously with magnetic force for $8 \mathrm{~h}$ and left to stand for $16 \mathrm{~h}$. The supernatant (leachate) was passed through a $0.45 \mu \mathrm{m}$ filter membrane for use. Subsequently, 20 cabbage seeds were selected and placed in a Petri dish with filter paper and $5 \mathrm{~mL}$ of supernatant was added. Than, petri dishes were incubated in an incubator under dark conditions at a constant temperature of $25^{\circ} \mathrm{C}$ for 3 days. Three parallel experiments were carried out for each leaching solution using seeds cultured in deionised water as a control group. The final seed germination index (SGI) was obtained by the following equation (B. Wang 2018; Gao 2010):

$$
\mathrm{SGI}=\frac{\text { Averagegerminationrate }_{\mathrm{LC}} * \text { Averagerootlength }_{\mathrm{LC}}}{\text { Averagegerminationrate }_{\mathrm{DW}} * \text { Averagerootlength }_{\mathrm{DW}}} * 100 \backslash \%
$$

LC denotes leachate and DW denotes deionised water. 
Physiological index test: Cabbage seeds were flotation with distilled water to remove dried out grains before germination, then placed in petri dishes lined with filter paper, $5 \mathrm{ml}$ of deionized water was added and germinated in a constant temperature incubator at $25^{\circ} \mathrm{C}$. After 24 hours select those with normal germination for hydroponics, with Hoagland nutrient solution $(\mathrm{pH}=6.8)$, with $5 \mathrm{ml}$ of catalyst leachate added to the nutrient solution, and seedlings with deionised water added to the culture solution were used as a control group; they were incubated in a constant temperature light incubator, set at $25^{\circ} \mathrm{C}$, for ten days.Determination of chlorophyll content: weigh $0.1 \mathrm{~g}$ of cut cabbage leaves, put into a mortar, add a small amount of calcium carbonate and quartz sand and $5 \mathrm{ml} 95 \%$ ethanol, grind into a homogenous slurry, continue to grind until the tissue turns white, filter through filter paper; rinse the residue and filter paper repeatedly with ethanol until colourless, then fix the volume to $25 \mathrm{ml}$. use $95 \%$ ethanol as blank, measure the absorbance at wavelengths of $665 \mathrm{~nm}, 649 \mathrm{~nm}, 470 \mathrm{~nm}$. The absorbance was measured at $470 \mathrm{~nm}$. The formula was calculated as follows:

$C_{a}=13.95 A_{665}-6.68 A_{649}(2)$

$C_{b}=24.96 A_{649-7.32 A_{665}(3)}$

$\mathrm{C}=\left(1000 \mathrm{~A}_{470}-2.05 \mathrm{C}_{\mathrm{a}}-114.8 \mathrm{C}_{\mathrm{b}}\right) / 245$ (4)

$\mathrm{CLP}=(\mathrm{C} * \mathrm{~V}) / 1000 \mathrm{~W}(5)$

$\mathrm{C}_{a}, \mathrm{C}_{\mathrm{b}}, \mathrm{C}, \mathrm{A}$ and CLP denote chlorophyll a, chlorophyll $\mathrm{b}$, chlorophyll concentration, absorbance and chlorophyll content $(\mathrm{mg} / \mathrm{g})$ respectively; $\mathrm{V}$ and $\mathrm{M}$ denote the volume of the extract and the fresh weight of the sample.

\subsection{Free radical capture experiments}

Before the photocatalytic degradation experiment started, a certain amount of free radical scavengers were added to the solution. Ammonium oxalate (AO), p-benzoquinone (BQ), isopropyl alcohol (IPA) and ferrous sulfate-ethylenediaminetetraacetic acid disodium salt ( $\mathrm{Fe}(\mathbb{\nabla}) / \mathrm{EDTA}-2 \mathrm{Na})$ were the scavengers of $\mathrm{h}^{+}, \mathrm{O}_{2}{ }^{-}, \cdot \mathrm{OH}$ and $\mathrm{H}_{2} \mathrm{O}_{2}$, respectively (Adam 2017; Wei Wang 2017). The addition of free radical scavengers would inhibit the degradation efficiency of antibiotics, and the degree of inhibition was proportional to the importance of the corresponding free radicals, that is, the greater the role played by the active species in the photocatalytic degradation process, the greater the degree of inhibition of the degradation effect of antibiotics after the addition of free radical scavengers.

\section{Results And Discussion}

\subsection{Structure and composition}

The crystal structures of the $\mathrm{CN}, 0.005 \mathrm{TCN}, 0.01 \mathrm{TCN}$ and $0.02 \mathrm{TCN}$ catalysts were tested by XRD. As shown in Fig. 1 at $13.0^{\circ}$ and $27.2^{\circ}$, the $0.005 \mathrm{TCN}, 0.01 \mathrm{TCN}$ and $0.02 \mathrm{TCN}$ samples have the same profile 
as $\mathrm{CN}$ with two significant diffraction peaks. The dominant peak at $27.2^{\circ}$ corresponds to the (002) crystal plane, which is due to the interlayer stacking reflection of the conjugated aromatic system. The peak at $13.0^{\circ}$ is the (100) plane, caused by the periodic build-up of layers in the graphite structure (Han 2018). Since no significant impurity peaks were observed in $\mathrm{xTCN}$, the doping of Tb ions may not affect the crystalline phase of $\mathrm{CN}$. The intensity of the diffraction peak of the $0.005 \mathrm{TCN}$ catalyst $\left(27.2^{\circ}\right)$ was significantly enhanced compared to $\mathrm{CN}$, indicating that the participation of $\mathrm{Tb}$ enhanced the degree of polymerisation and crystallisation of the $\mathrm{g}-\mathrm{C}_{3} \mathrm{~N}_{4}$ interlayer network. However, the intensity of the $27.2^{\circ}$ characteristic peak decreases with increasing $\mathrm{Tb}$ doping content, which may be due to the graphite diffraction intensity of the tri-s-triazinyl linker becoming weaker with increasing amounts of Tb incorporation (Jin 2019).

The molecular structure information of the prepared CN, 0.005 TCN, 0.01 TCN and 0.02 TCN was investigated using FTIR spectroscopy.As shown in Fig. 2, the CN shows three main absorption regions at $805 \mathrm{~cm}^{-1}, 1200-1700 \mathrm{~cm}^{-1}$ and $3171 \mathrm{~cm}^{-1}$. The sharp characteristic peak at $805 \mathrm{~cm}^{-1}$ is mainly caused by the bending vibration of the triazine unit. The series of peaks in the $1200-1700 \mathrm{~cm}^{-1}$ range are the result of aromatic $\mathrm{C}-\mathrm{N}$ stretching vibrations and the deposition of $\mathrm{C}=\mathrm{N}$ bonds (Qi 2016). The stretching vibrations of the $\mathrm{N}-\mathrm{H}$ group and the surface adsorption of water molecules give rise to a broad absorption band at $3171 \mathrm{~cm}^{-1}$. The FTIR profiles exhibited by xTCN and $\mathrm{CN}$ are essentially identical, except for the centre of the band between 2290 and $2390 \mathrm{~cm}^{-1}$ which is due to $\mathrm{C} \equiv \mathrm{N}$ stretching vibrations,indicating that the $\mathrm{C} \equiv \mathrm{N}$ triple bond is formed and not due to aromatic $\mathrm{C}-\mathrm{N}$ stretching vibrations. The characterization results of the FTIR spectra can be explained by the addition of Tb ions breaking some of the triazine rings of $\mathrm{g}-\mathrm{C}_{3} \mathrm{~N}_{4}$, transforming the sp2 $\mathrm{C}-\mathrm{N}$ single bond into a $\mathrm{C} \equiv \mathrm{N}$ triple bond (Wang 2019).

The surface elemental composition and valence state of the 0.01TCN material was further confirmed by XPS analysis. The main peaks of the elements carbon, nitrogen, terbium and oxygen were observed through the measured spectra of $0.01 \mathrm{TCN}$, as shown in Fig. 3d. The high-resolution spectra of $\mathrm{C} 1 \mathrm{~s}$ at 284.8, 285.4, and $288.1 \mathrm{eV}$ are attributed to $\mathrm{sp} 2$ hybridized $\mathrm{C}=\mathrm{C}, \mathrm{C}=$ and $\mathrm{N}-\mathrm{C}=\mathrm{N}$, respectively, which are derived from coupled g- $\mathrm{C}_{3} \mathrm{~N}_{4}$. The peak carbon atom in a pure carbon environment is $284.8 \mathrm{eV}$. The peak of $0.01 \mathrm{TCN}$ at $285.4 \mathrm{eV}$ is the $\mathrm{C}-\mathrm{NH}_{\mathrm{x}}$ of the heptane molecule $(\mathrm{x}=1,2)$. The main peak of $0.01 \mathrm{TCN}$ located at $288.1 \mathrm{eV}$ was assigned to $\mathrm{N}-\mathrm{C}=\mathrm{N}$, that further verifies the presence of $\mathrm{C} \equiv \mathrm{N}$, as the binding energy of $\mathrm{C} \equiv \mathrm{N}$ is similar to that of $\mathrm{C}-\mathrm{NH}_{\mathrm{x}}$ (Fig. 3a). The high resolution profile of $\mathrm{N} 1 \mathrm{~s}$ can be fitted to three peaks at $398.4 \mathrm{eV}, 399.9 \mathrm{eV}$ and $400.9 \mathrm{eV}$ respectively. The peaks at $398.7 \mathrm{eV}$ and $399.9 \mathrm{eV}$ can be identified as sp2 hybridized $\mathrm{N}$, where $398.7 \mathrm{eV}$ corresponds to $\mathrm{N}$ in the $\mathrm{N}=\mathrm{C}$ bond and $399.9 \mathrm{eV}$ belongs to $\mathrm{N}$ in the $\mathrm{N}-(\mathrm{C})_{3}$ bond. Due to the incomplete polymerization of melamine and the adsorption of surface water, the peak with binding energy at $401.0 \mathrm{eV}$ belongs to the amino functional group $(\mathrm{N}-\mathrm{Hx}, \mathrm{X}=1,2)$ (Fig. 3b) (Zhang 2019). The positive charge localization in the heterocycle leads to the weakest peak at 404.8 $\mathrm{eV}$. The peak around $152.8 \mathrm{eV}$ in the Fig. $3 \mathrm{c}$ belongs to $\mathrm{Tb}_{4} \mathrm{~d}_{5 / 2}$, indicating the presence of $\mathrm{Tb}^{3+}$ ions; the doped Tb is present in the form of Tb(III) (Fig. 3c) (Lu 2017). 


\subsection{Morphological analysis}

The microstructural features of $\mathrm{CN}, \mathrm{HCN}, 0.005 \mathrm{TCN}, 0.01 \mathrm{TCN}$ and $0.02 \mathrm{TCN}$ catalysts were analyzed by transmission electron microscopy. For $\mathrm{HCN}$, it exhibits a completely different morphology from that of $\mathrm{CN}$. It exhibits a typical laminar porous structure and many pores of different diameters are observed in the layer structure. There are several reasons for this to happen: When nitric acid solution is added to melamine, the ionized $\mathrm{H}^{+}$is transferred to the nitrogen atoms on the melamine triazine ring, which then causes the melamine to be protonated. In the heating process, the nitrate anion connected with the protonated melamine cation will decompose at high speed to produce a large amount of nitrogen. Nitrogen can be used as a bubble template to form mesoporous structures of CN. As shown in Fig. 4, 0.005TCN, 0.01TCN and 0.02TCN have a microstructure similar to that of HCN(Fig. 4) (Liu 2016; Xie 2018a).

When the photocatalyst is energized by light, $\mathrm{e}^{-}$in the valence band is excited to jump into the conduction band, resulting in $\mathrm{e}^{-}$and $\mathrm{h}^{+}$pairs. When $\mathrm{e}^{-}$and $\mathrm{h}^{+}$are compounded in the bulk phase or surface of the photocatalyst, some energy is released in the form of fluorescence. Usually, the complexation rate of photogenerated $\mathrm{e}^{-}$and $\mathrm{h}^{+}$is proportional to the fluorescence intensity, and the PL characterization was performed to study the photogenerated carrier migration and separation of the prepared TCN samples by $\mathrm{HCN}$ and TCN samples, as shown in Fig. 5. From the figure, it can be seen that both HCN and TCN catalysts have a broad peak at around $460 \mathrm{~nm}$, that belongs to the band photoluminescence specific to the photogenerated carriers of $\mathrm{g}-\mathrm{C}_{3} \mathrm{~N}_{4}$ polymer, and it can be found from the figure that the separation of photogenerated $\mathrm{e}^{-}$and $\mathrm{h}^{+}$in the photocatalyst doped with Tb elements is significantly better than that of $\mathrm{CN}$ (Bui 2020); The order of luminous intensity is: $\mathrm{HCN}>0.02 \mathrm{TCN}>0.005 \mathrm{TCN}>0.01 \mathrm{TCN}$. This implies that the separation and transport rates of photogenerated carriers are significantly increased after $\mathrm{Tb}$ doping, and the $\mathrm{Tb}$ element doping and mesoporous structure have a significant effect on improving the separation and transport of charges.

\subsection{Analysis of the light absorption properties of $\mathrm{Tb} / \mathrm{g}-\mathrm{C}_{3} \mathrm{~N}_{4}$}

The light absorption ability of the prepared samples was measured by UV-Vis spectrophotometer,and the light absorption performance of the catalyst has a great influence on its degradation of organic pollutants. The absorption edge of pure $\mathrm{CN}$ can be obtained from Fig. 6 to be about $450 \mathrm{~nm}$, which is consistent with the previous literature. However, the optical absorption edges of 0.005TCN and 0.02TCN were shifted to $475 \mathrm{~nm}$, and 0.01TCN was further red-shifted to $490 \mathrm{~nm}$ (Bui 2020). In addition, 0.005TCN, 0.01TCN and 0.02TCN exhibit stronger light absorption than $\mathrm{g}-\mathrm{C}_{3} \mathrm{~N}_{4}$ in the visible range, which may be due to the synergistic effect of Tb doping into $\mathrm{g}-\mathrm{C}_{3} \mathrm{~N}_{4}$ to form a heterojunction.

\subsection{Photocatalytic performance}

In order to determine the optimal doping concentration of terbium in $\mathrm{g}-\mathrm{C}_{3} \mathrm{~N}_{4}$, the degradation experiments of TC (25 mg/L) and TYL (25 mg/L) using photocatalysts with different terbium doping concentrations 
under simulated solar irradiation were carried out. Figure 7 shows the photodegradation rate curves of the photocatalytic effect of solar simulated light expressed by CN, 0.01TCN, 0.02TCN and 0.005 TCN for TYL and TC, respectively. According to the blank test, TC and TYL could hardly be degraded under simulated solar irradiation without a catalyst, which means that it is difficult to photolyze TC and TYL without a photocatalyst. The photocatalytic activity of $\mathrm{CN}$ was relatively low after 90 min of simulated sunlight irradiation, degrading only $52.1 \%$ TYL and $64.1 \%$ TC. In order to make a more visual comparison of the photocatalytic activity of $\mathrm{CN}$ and $\mathrm{XTCN}$; the results of the photocatalytic degradation of antibiotic by $\mathrm{CN}$ and TCN samples were investigated using quasi-level kinetics, the equations are as follows:

$-\ln \left(\mathrm{C} / \mathrm{C}_{0}\right)=\mathrm{kt}(6)$

where $\mathrm{C}$ is the concentration of TYL and TC at irradiation time $t(\min ) ; \mathrm{C}_{0}$ is the initial concentration of TYL and TC; and $k$ denotes the apparent reaction rate constant. CN degraded TYL and TC with $k$ values of 0.0127 and $0.0095 ; 0.01$ TCN degraded TYL and TC with $k$ values of 0.0271 and 0.0239 .

It can be noted from the figure that the photocatalytic activity of xTCN increases and then decreases with the increase of the molar concentration of $\mathrm{Tb}$ doping,and the possible reasons for this situation are discussed below. As the rare earth trivalent cation $\left(\mathrm{Tb}^{3+}\right)$ has an incompletely occupied $4 \mathrm{f}$ orbital, it is thermodynamically feasible for $\mathrm{Tb}^{3+}$ to be reduced by photogenerated electrons. Therefore, the use of $\mathrm{Tb}^{3+}$ as a trapping agent is effective in trapping the electrons on VB and restoring them to $\mathrm{Tb}^{2+}$. Subsequently, the $\mathrm{Tb}^{2+}$ ion is oxidised back to $\mathrm{Tb}^{3+}$ by $\mathrm{O}_{2}$ in the ambient solution.

$\mathrm{Tb}^{3+}+\mathrm{e}^{-} \rightarrow \mathrm{Tb}^{2+}(7)$

$\mathrm{Tb}^{2+}+\mathrm{O}_{2} \rightarrow \mathrm{Tb}^{3+}+\hat{\mathrm{A}} \cdot \mathrm{O}_{2}^{-}(8)$

Therefore, by doping with an appropriate concentration of $\mathrm{Tb}^{3+}$ ions can be used as an electron trapping agent, which not only promotes the rapid transfer of photogenerated electrons, but also reduces the complexation of electrons with holes, thus the quantum efficiency is increased. However, when the molar mass ratio of the doping of $\mathrm{Tb}\left(\mathrm{NO}_{3}\right)_{3} \cdot 5 \mathrm{H}_{2} \mathrm{O}$ exceeded the optimum value of $0.01 \%$, the degradation rate of the antibiotic decreased,as shown in Fig. 7. This situation is explained by the reduction of $\mathrm{Tb}^{3+}$ to $\mathrm{Tb}^{2+}$ by electrons, which means that an excess of terbium ions acts as a complex centre for electron-hole pairs, reducing the number of photogenerated electrons that would otherwise react with oxygen molecules to form superoxide radicals. At the same time, too much terbium ions can occupy the active sites on the catalyst surface, which is not conducive to improving photocatalytic activity. Therefore, doping with the right amount of terbium ions can improve the photocatalytic activity of the photocatalyst.

\subsection{Stability evaluation}

For photocatalysts, their stability and reproducibility are important factors affecting its reagent application. The stability as well as the reproducibility of the prepared $0.01 \mathrm{TCN}$ catalysts were confirmed 
by running the degraded antibiotics three times under the same conditions. The relative concentration $\left(\mathrm{C} / \mathrm{C}_{0}\right)$ of the antibiotics solution under simulated solar irradiation is shown in Fig. 8 as a function of time repeated over three cycles. the antibiotics photodegradation efficiency did not change significantly over the three cycles. The results show that the $0.01 \mathrm{TCN}$ photocatalyst has very good stability in the photocatalytic degradation process.

\subsection{Toxicity test of leaching solution}

The mean root length (AL) and seed germination rate (SR) of Chinese cabbage seeds were obtained by seed germination experiment, and the germination index was calculated according to formula 1. Figure 9a shows the germination conditions of different catalyst leaching solution as culture medium. In the seed germination experiment, the average root length (Al), germination percentage (Sr) and germination index (SGI) of Chinese cabbage seeds are shown in Table 1. It can be seen from Table 1 that the germination index of Chinese cabbage seeds cultivated with different catalyst leaching solutions fluctuated little, and the influence of different catalyst leaching solutions on the seed germination index was negligible. Figure $9 \mathrm{~b}$ shows the growth of Chinese cabbage seedlings with different catalyst leaching solutions added to the culture medium. It can be seen from Fig. $9 \mathrm{c}$ that different catalyst leaching solutions have no inhibitory effect on Chinese cabbage seedlings and their chlorophyll content is almost the same, which does not affect the absorption and utilization of light. Therefore, it can be concluded that $\mathrm{CN}$ and TCN catalysts have little effect on seed germination.

\subsection{Photocatalytic reaction mechanism}

In general, the type of radicals originating from photoexcited electrons and holes directly determines the photocatalytic degradation mechanism. So we have revealed the mechanism of the photocatalytic reaction by examining the main oxides produced in the degradation reaction. $\mathrm{O}_{2}, \cdot \mathrm{OH}, \mathrm{H}_{2} \mathrm{O}_{2}$ and $\mathrm{h}^{+}$are the main oxide species involved in the photocatalytic reaction process. Therefore, in order to identify the active species that mainly participate in the reaction during catalysis, different bursting agents are added to the reaction solution to neutralise the free radicals (Jiang 2017). The main active species during the degradation reactions were studied by using isopropyl alcohol (IPA), ammonium oxalate (AO), benzoquinone (BQ) and Fe(II)-EDTA as trapping agents for $\cdot \mathrm{OH}, \mathrm{h}^{+}, \mathrm{O}_{2}{ }^{-}$and $\mathrm{H}_{2} \mathrm{O}_{2}$. as shown in Fig. 10. The degradation of TC decreased from $83.5-10.8 \%, 78.4 \%, 76.2 \%$ and $47.2 \%$ after the addition of BQ, IPA, $\mathrm{AO}$ and $\mathrm{Fe}(\mathrm{II})$-EDTA respectively,indicating that the addition of $\mathrm{BQ}$ had the greatest effect on the degradation reaction of antibiotics, followed by Fe(II)-EDTA; finally AO and IPA had the least effect,thus indicating that $\cdot \mathrm{O}_{2}{ }^{-}$was the main active species. The slight decrease in degradation rate caused by IPA, $\mathrm{Fe}(\mathrm{II})$-EDTA and $\mathrm{AO}$ implies that $\cdot \mathrm{OH}, \mathrm{H}_{2} \mathrm{O}_{2}$ and $\mathrm{h}^{+}$are also involved in the degradation reaction. The order

of importance of the oxide species is: $\cdot \mathrm{O}_{2}{ }^{-}>\mathrm{H}_{2} \mathrm{O}_{2}>\cdot \mathrm{OH}>\mathrm{h}^{+}$; so $\cdot \mathrm{O}_{2}{ }^{-}$and $\mathrm{H}_{2} \mathrm{O}_{2}$ radicals play an important role in the photocatalytic process and act as the main oxide species. 
Based on the above photocatalytic performance tests, and free radical capture experiments, a preliminary explanation of the reaction mechanism of $\mathrm{Tb}^{3+} / \mathrm{g}-\mathrm{C}_{3} \mathrm{~N}_{4}$ photocatalysis is presented in Fig. 11 . According to previous reports $C N$ has a $C B$ and VB of $-1.4 \mathrm{eV}$ and $+1.3 \mathrm{eV}$ (Guo 2019) respectively. Since the reduction potential of photogenerated electrons is more negative than the redox potential of $\mathrm{O}_{2} / \cdot \mathrm{O}_{2}{ }^{-}(0.33$ $\mathrm{eV}), \mathrm{O}_{2}$ is more easily reduced by electrons to form $\cdot \mathrm{O}_{2}{ }^{-}$. The redox potentials of $\cdot \mathrm{OH} / \mathrm{OH}^{-}(+1.99 \mathrm{eV})$ and $\cdot \mathrm{OH} / \mathrm{H}_{2} \mathrm{O}(+2.27 \mathrm{eV})$ are more positive than the potential of the highest occupied molecular orbital of $\mathrm{CN}$ (Yang 2019), so $\mathrm{h}+$ located in VB cannot oxidize $\mathrm{H}_{2} \mathrm{O}$ or $\mathrm{OH}^{-}$to produce $\cdot \mathrm{OH}$ that $\cdot \mathrm{OH}$ is produced from $\mathrm{O}_{2}{ }^{-}$. During the photocatalytic degradation process, we found that during the adsorption equilibrium phase,TCN catalysts were able to provide a greater abundance of photocatalytic active sites compared to $\mathrm{CN}$ due to the mesoporous structure of the TCN catalysts enabling them to expose more geometric surfaces, resulting in a larger specific surface area.In addition, the presence of a mesoporous structure increases the specific surface area,which improves the adsorption and diffusion processes during the reaction. 0.01TCN catalysts with a high specific surface area enable molecules such as pollutants or oxygen to come into contact with the catalyst surface more effectively, while generating more efficient capture of photogenerated $\mathrm{e}^{-}$and $\mathrm{h}^{+}$for oxidation or reduction reactions, thus improving the photocatalytic effect. The hollow pores in the mesoporous structure allow the incident light to be refracted and scattered several times inside the catalyst, allowing more contact with the incident light and improving the utilisation of the light. Mesoporous structures can also reduce carrier complexation by reducing the migration distances of electrons and holes and speeding up the transfer of photogenerated $\mathrm{e}^{-}$and $\mathrm{h}^{+}$to locations at the edge of the catalyst surface (Xie 2018b). Based on the above analysis,a photocatalytic mechanism for the photocatalytic degradation of antibiotics by $0.01 \mathrm{TCN}$ catalyst is proposed. As shown in the figure, $\mathrm{e}^{-}$in the valence band of the $0.01 \mathrm{TCN}$ sample is excited to jump to the conduction band, forming $\mathrm{e}^{-}$and $\mathrm{h}^{+}$pairs. When the $\mathrm{g}-\mathrm{C}_{3} \mathrm{~N}_{4}$ polymer is doped with $\mathrm{Tb}$, a Tb impurity energy level is formed between its conduction band and valence band,which means that $\mathrm{e}$ - in the 0.01TCN sample can both jump to the Tb impurity energy level and transfer to the conduction band of $\mathrm{g}$ $\mathrm{C}_{3} \mathrm{~N}_{4}$, which facilitates the separation of $\mathrm{e}^{-}$and $\mathrm{h}^{+}$(Zhou 2019). A portion of the $\mathrm{e}^{-}$located in the conduction band and the $\mathrm{Tb}(\mathrm{III})$ impurity energy level then moves to the catalyst surface, which in turn reduces the $\mathrm{O}_{2}$ molecules adsorbed on the catalyst surface to $\cdot \mathrm{O}_{2}{ }^{-}$.Some of these $\cdot \mathrm{O}_{2}{ }^{-}$react with $\mathrm{H}^{+}$to form $\mathrm{H}_{2} \mathrm{O}_{2}$ and $\cdot \mathrm{OH}$. A series of free radicals are generated, which finally decompose pollutants such as TYC into $\mathrm{H}_{2} \mathrm{O}, \mathrm{CO}_{2}$ (Shi 2015) and other inorganic substances to reduce pollution. Compared to pure g$\mathrm{C}_{3} \mathrm{~N}_{4}$, the impurity energy level generated by $\mathrm{Tb}$ in the $0.01 \mathrm{TCN}$ sample provides an alternative transfer pathway for $\mathrm{e}^{-}$, which more effectively inhibits the compounding of photogenerated electron holes, thus improving the photocatalytic activity of the sample.

\section{Conclusion}

Overall, The new xTCN catalyst is a very promising photocatalyst, using a mixture of melamine and $\mathrm{Tb}\left(\mathrm{NO}_{3}\right)_{3}$ as precursor calcined at $550^{\circ} \mathrm{C}$ for 2 hours. The prepared $\mathrm{xTCN}$ samples showed very good 
photocatalytic activity for the degradation of antibiotics (TC and TYL) under simulated sunlight conditions and it has excellent stability. Through characterisation,photocatalytic performance testing and radical capture experiments, a potential mechanism for the improvement of photocatalytic efficiency of $\mathrm{Tb} / \mathrm{g}-\mathrm{C}_{3} \mathrm{~N}_{4}$ materials is proposed. The improved photocatalytic performance is attributed to the wider visible light response range and the synergistic effect with terbium dopants, which inhibits electron-hole complexation and improves photocatalytic performance. In leachate toxicity experiments, it had little effect on the germination of plants and the chlorophyll content of seedlings, indicating negligible leaching toxicity of $x T C N$. This shows that Tb-doped $g-\mathrm{C}_{3} \mathrm{~N}_{4}$ will provide a new aid to the photocatalytic degradation of effluents.

\section{Declarations}

Ethics approval and consent to participate

Approval was obtained from the ethics committee of Northeast Electric Power University. The procedures used in this study adhere to the tenets of the Declaration of Helsinki.

Consent for publication

The participant has consented to the submission of the case report to the journal.

Availability of data and materials: The datasets used and/or analysed during the current study are available from the corresponding author on reasonable request.

Competing interests: The datasets used and/or analysed during the current study are available from the corresponding author on reasonable request.

Funding

There was no funding or institutional funding for this study.

Authors' contributions

All authors contributed to the study conception and design. Material preparation, data collection and analysis were performed by Bing Wang, Qingtong Cao, Guomin Li and Jian Zhang. The first draft of the manuscript was written by Bing Wang and all authors commented on previous versions of the manuscript. All authors read and approved the final manuscript.

Acknowledgements

The authors want to thank Northeast Electric Power University for the support.

\section{References}


1. Adam W J S K, Karthikeyan F L S (2017) Cobalt promoted $\mathrm{TiO}_{2} / \mathrm{GO}$ for the photocatalytic degradation of oxytetracycline and Congo Red. Applied Catalysis B: Environmental 201: 159-168.

2. Amandeep $\mathrm{K}$, Sushil Kumar $\mathrm{K}$ (2016) $\mathrm{Bi}_{2} \mathrm{WO}_{6}$ nanocuboids: An efficient visible light active photocatalyst for the degradation of levofloxacin drug in aqueous phase. Chemical Engineering Journal 302: 194-203.

3. Briones R M, Sarmah A K, Padhye L P (2016) A global perspective on the use, occurrence, fate and effects of anti-diabetic drug metformin in natural and engineered ecosystems. Environmental Pollution 219: 1007-1020.

4. Bui T S, Bansal P, Lee B, Mahvelati-Shamsabadi T, Soltani T (2020) Facile fabrication of novel Badoped g- $\mathrm{C}_{3} \mathrm{~N}_{4}$ photocatalyst with remarkably enhanced photocatalytic activity towards tetracycline elimination under visible-light irradiation. Applied Surface Science 506: 144184.

5. Cerrato E, Gionco C, Berruti I, Sordello F, Calza P, Paganini M C (2018) Rare earth ions doped ZnO: Synthesis, characterization and preliminary photoactivity assessment. Journal of Solid State Chemistry 264: 42-47.

6. Chen X, Zhang J, Fu X, Antonietti M, Wang X (2009) Fe-g- $\mathrm{C}_{3} \mathrm{~N}_{4}$-Catalyzed Oxidation of Benzene to Phenol Using Hydrogen Peroxide and Visible Light. Journal of the American Chemical Society 131 (33): 11658-11659.

7. Ding Z, Chen X, Antonietti M, Wang X (2010) Synthesis of Transition Metal-Modified Carbon Nitride Polymers for Selective Hydrocarbon Oxidation. ChemSusChem: n/a-n/a.

8. Faisal M, Farid A A I, Mohamed El-Toni M S A (2016) Synthesis of highly dispersed Silver Doped g$\mathrm{C}_{3} \mathrm{~N}_{4}$ nanocomposites with enhanced visible-light photocatalytic activity. Materials \& Design 98: 223230.

9. Fu J, Xu Q, Low J, Jiang C, Yu J (2019) Ultrathin 2D/2D WO ${ }_{3} / g-C_{3} N_{4}$ step-scheme $\mathrm{H}_{2}$-production photocatalyst. Applied Catalysis B: Environmental 243: 556-565.

10. Gao M, Li B, Yu A, Liang F, Yang L, Sun Y (2010) The effect of aeration rate on forced-aeration composting of chicken manure and sawdust. Bioresource Technology 101 (6): 1899-1903.

11. Gao X, Dai J F Y (2018) Hydrothermal synthesis of series Cu-doped $\mathrm{Bi}_{2} \mathrm{WO}_{6}$ and its application in photo-degradative removal of phenol in wastewater with enhanced efficiency. Journal of Molecular Liquids 256: 267-276.

12. Gao, Zhang W, Zhou H, Chen D (2018) Magnetic composite $\mathrm{Fe}_{3} \mathrm{O}_{4} / \mathrm{CeO}_{2}$ for adsorption of azo dye. Journal of Rare Earths 36 (9): 986-993.

13. Guo F, Shi W, Li M, Shi Y, Wen H (2019) 2D/2D Z-scheme heterojunction of CulnS $2 / g-C_{3} N_{4}$ for enhanced visible-light-driven photocatalytic activity towards the degradation of tetracycline. Separation and Purification Technology 210: 608-615.

14. Han T, Xie C M, Meng Y J, Wei $Y$ (2018) Synthesized $\mathrm{MnO}_{2} / \mathrm{Ag} / \mathrm{g}-\mathrm{C}_{3} \mathrm{~N}_{4}$ composite for photoreduction carbon dioxide under visible light. Journal of Materials Science: Materials in Electronics 29 (24): 20984-20990. 
15. Hu S, Zhou F, Wang L, Zhang J (2011) Preparation of $\mathrm{Cu}_{2} \mathrm{O} / \mathrm{CeO}_{2}$ heterojunction photocatalyst for the degradation of Acid Orange 7 under visible light irradiation. Catalysis Communications 12 (9): 794-797.

16. Jiang G, X Li (2017) Monodisperse Bismuth Nanoparticles DecoratedGraphitic Carbon Nitride: Enhanced Visible-Light-Response Photocatalytic NO Removal and Reaction Pathway. Applied Catalysis B: Environmental 205: 532-540.

17. Jin C, Li Z, Zhang Y, Wang M, Wu Z, Xie Y (2019) The construction of $g-\mathrm{C}_{3} \mathrm{~N}_{4} / \mathrm{Sm}^{2+}$ doped $\mathrm{Bi}_{2} \mathrm{WO}_{6}$ 2D/2D Z-scheme heterojunction for improved visible-light excited photocatalytic efficiency. Separation and Purification Technology 224: 33-43.

18. Karageorgou E, Armeni M, Moschou I, Samanidou V (2014) Ultrasound-assisted dispersive extraction for the high pressure liquid chromatographic determination of tetracyclines residues in milk with diode array detection. Food Chemistry 150: 328-334.

19. Li G M, Wang B, Zhang J, Wang R, Liu H (2020) Er-doped g- $\mathrm{C}_{3} \mathrm{~N}_{4}$ for photodegradation of tetracycline and tylosin: High photocatalytic activity and low leaching toxicity. Chemical Engineering Journal 391: 123500.

20. Li G M, Wang R, Wang B, Zhang J (2020) Sm-doped mesoporous g- $\mathrm{C}_{3} \mathrm{~N}_{4}$ as efficient catalyst for degradation of tylosin: Influencing factors and toxicity assessment. Applied Surface Science 517: 146212 .

21. Li J, Yin Y, Liu E, Ma Y, Wan J, Fan J, et al. (2017) In situ growing $\mathrm{Bi}_{2} \mathrm{MoO}_{6}$ on $\mathrm{g}-\mathrm{C}_{3} \mathrm{~N}_{4}$ nanosheets with enhanced photocatalytic hydrogen evolution and disinfection of bacteria under visible light irradiation. Journal of Hazardous Materials 321: 183-192.

22. Liu J, Yan J, Ji H, Xu Y, Huang L, Li Y, et al. (2016) Controlled synthesis of ordered mesoporous g$\mathrm{C}_{3} \mathrm{~N}_{4}$ with a confined space effect on its photocatalytic activity. Materials Science in Semiconductor Processing 46: 59-68.

23. Lu D, Yang M, Fang P, Li C, Jiang L (2017) Enhanced photocatalytic degradation of aqueous phenol and $\mathrm{Cr}(\mathrm{VI})$ over visible-light-driven $\mathrm{Tb}_{\mathrm{x}} \mathrm{O}_{\mathrm{y}}$ loaded $\mathrm{TiO}_{2}$-oriented nanosheets. Applied Surface Science 399: 167-184.

24. Ma S, Zhan S, Xia Y, Wang P, Hou Q, Zhou Q (2019) Enhanced photocatalytic bactericidal performance and mechanism with novel $\mathrm{Ag} / \mathrm{ZnO} / \mathrm{g}-\mathrm{C}_{3} \mathrm{~N}_{4}$ composite under visible light. Catalysis Today 330: 179-188.

25. Mazumder P, Khwairakpam M, Kalamdhad A S (2020) Bio-inherent attributes of water hyacinth procured from contaminated water body-effect of its compost on seed germination and radicle growth. Journal of Environmental Management 257: 109990.

26. Mishra S, Tripathi R, Srivastava S, Dwivedi S, Trivedi P (2009) Thiol metabolism play significant role during cadmium detoxification by Ceratophyllum demersum L. Bioresource Technology 100 (7): 2155-2161. 
27. Mobin M, Khan N A (2007) Photosynthetic activity, pigment composition and antioxidative response of two mustard (Brassica juncea) cultivars differing in photosynthetic capacity subjected to cadmium stress. Journal of Plant Physiology 164 (5): 601-610.

28. Qi F, Li Y, Wang Y, Wang Y, Liu S, Zhao X (2016) Ag-Doped g- $\mathrm{C}_{3} \mathrm{~N}_{4}$ film electrode: fabrication, characterization and photoelectrocatalysis property. RSC Advances.

29. Shi L, Wang T, Zhang H, Chang K, Ye J (2015) Electrostatic Self-Assembly of Nanosized Carbon Nitride Nanosheet onto a Zirconium Metal-Organic Framework for Enhanced Photocatalytic $\mathrm{CO}_{2}$ Reduction. Advanced Functional Materials 25 (33): 5360-5367.

30. Sun L D, Dong H, Zhang P Z (2015) Upconversion of Rare Earth Nanomaterials. Annual Review of Physical Chemistry 66: 619-642.

31. Tang J, Chen X, Liu Y, Gong W, Peng Z, Cai T, et al. (2013) Samarium-doped mesoporous $\mathrm{TiO}_{2}$ nanoparticles with improved photocatalytic performance for elimination of gaseous organic pollutants. Solid State Sciences 15: 129-136.

32. Tripathi D K, Singh V P, Prasad S M, Chauhan D K, Kishore Dubey N, Rai A K (2015) Silicon-mediated alleviation of $\mathrm{Cr}(\mathrm{VI})$ toxicity in wheat seedlings as evidenced by chlorophyll florescence, laser induced breakdown spectroscopy and anatomical changes. Ecotoxicology and Environmental Safety 113: 133-144.

33. Vignesh C, Bhethanabotla D, Kuhn (2017) Assessment of mechanisms for enhanced performance of $\mathrm{Yb} / \mathrm{Er} / \mathrm{titania}$ photocatalysts for organic degradation: Role of rare earth elements in the titania phase. Applied Catalysis B: Environmental 202: 156-164.

34. Wan Kuen J, Santosh Kumar Salvador Eslava T, Surendar (2018) Construction of $\mathrm{Bi}_{2} \mathrm{WO}_{6} / \mathrm{RGO} / \mathrm{g}$ $\mathrm{C}_{3} \mathrm{~N}_{4}$ 2D/2D/2D hybrid Z-scheme heterojunctions with large interfacial contact area for efficient charge separation and high-performance photoreduction of $\mathrm{CO}_{2}$ and $\mathrm{H}_{2} \mathrm{O}$ into solar fuels. Applied Catalysis B: Environmental 239: 586-598.

35. Wang B, Li G, Cai C, Zhang J, Liu H (2018) Assessing the safety of thermally processed penicillin mycelial dreg following the soil application: Organic matter's maturation and antibiotic resistance genes. Science of The Total Environment 636: 1463-1469.

36. Wang B, Yan J, Li G, Zhang J, Zhang L, Li Z, et al. (2020) Risk of penicillin fermentation dreg: Increase of antibiotic resistance genes after soil discharge. Environmental Pollution 259: 113956.

37. Wang F L, Feng Y P, Chen P, Wang Y F, Yuehan S, Zhang Q (2018) Corrigendum to "Photocatalytic degradation of fluoroquinolone antibiotics using ordered mesoporous $\mathrm{g}-\mathrm{C}_{3} \mathrm{~N}_{4}$ under simulated sunlight irradiation: Kinetics, mechanism, and antibacterial activity elimination" . Applied Catalysis B: Environmental 238: 673.

38. Wang F, Feng Y (2018) Photocatalytic degradation of fluoroquinolone antibiotics using ordered mesoporous $\mathrm{g}-\mathrm{C}_{3} \mathrm{~N}_{4}$ under simulated sunlight irradiation: Kinetics, mechanism, and antibacterial activity elimination. Applied Catalysis B: Environmental 227: 114-122. 
39. Wang J C, Li C, Xing C Y, Zhang Y P, Shi W (2017) Porous Mn Doped g- $\mathrm{C}_{3} \mathrm{~N}_{4}$ Photocatalysts for Enhanced Synergetic Degradation under Visible-Light Illumination. Journal of Hazardous Materials 339: 43-53.

40. Wang W J, Li G Y, An T C (2018) Photocatalytic hydrogen evolution and bacterial inactivation utilizing sonochemical-synthesized $\mathrm{g}-\mathrm{C}_{3} \mathrm{~N}_{4} /$ red phosphorus hybrid nanosheets as a wide-spectralresponsive photocatalyst: The role of type I band alignment. Applied Catalysis B: Environmental 238: 126-135.

41. Wang Y, Zhang Y, Zhao S, Huang W, Chen Y, Yuan (2019) Bio-template synthesis of Mo-doped polymer carbon nitride for photocatalytic hydrogen evolution. Applied Catalysis B: Environmental 248: 44-53.

42. Wei Wang, Lu C (2017) Compact and Uniform $\mathrm{TiO}_{2} @ g-\mathrm{C}_{3} \mathrm{~N}_{4}$ Core-Shell Quantum Heterojunction for Photocatalytic Degradation of Tetracycline Antibiotics. Applied Catalysis B: Environmental 217: 5764.

43. Wen X, Niu C, Guo H, Zhang L, Liang C, Zeng G (2018) Photocatalytic degradation of levofloxacin by ternary $\mathrm{Ag}_{2} \mathrm{CO}_{3} / \mathrm{CeO}_{2} / \mathrm{AgBr}$ photocatalyst under visible-light irradiation: Degradation pathways, mineralization ability, and an accelerated interfacial charge transfer process study. Journal of Catalysis 358: 211-223.

44. Xie L, Ni J, Tang B, He G, Chen H (2018a) A self-assembled 2D/2D-type protonated carbon nitridemodified graphene oxide nanocomposite with improved photocatalytic activity. Applied Surface Science 434: 456-463.

45. Xie L, Ni J, Tang B, He G, Chen H (2018b) A self-assembled 2D/2D-type protonated carbon nitridemodified graphene oxide nanocomposite with improved photocatalytic activity. Applied Surface Science 434: 456-463.

46. Xu D, Li X, Liu J, Huang L (2013) Synthesis and photocatalytic performance of europium-doped graphitic carbon nitride. Journal of Rare Earths 31 (11): 1085-1091.

47. Yan S C, Li Z S, Zou Z G (2009) Photodegradation Performance of g- $\mathrm{C}_{3} \mathrm{~N}_{4}$ Fabricated by Directly Heating Melamine. Langmuir 25 (17): 10397-10401.

48. Yan S, Shi Y, Tao Y (2019) Enhanced persulfate-mediated photocatalytic oxidation of bisphenol A using bioelectricity and a g- $\mathrm{C}_{3} \mathrm{~N}_{4} / \mathrm{Fe}_{2} \mathrm{O}_{3}$ heterojunction. Chemical Engineering Journal 359: 933-943.

49. Yang Y, Zhang C, Huang D, Zeng G, Huang J, Lai C (2019) Boron nitride quantum dots decorated ultrathin porous $\mathrm{g}-\mathrm{C}_{3} \mathrm{~N}_{4}$ : Intensified exciton dissociation and charge transfer for promoting visiblelight-driven molecular oxygen activation. Applied Catalysis B: Environmental 245: 87-99.

50. Zhang F, Lu W, Xiao G, Liu Z, Xing F, Lyu C (2015) The Effect of pH Values on the Synthesis, Microstructure and Photocatalytic Activity of $\mathrm{Ce}-\mathrm{Bi}_{2} \mathrm{O}_{3}$ by a Two-Step Hydrothermal Method. Photochemistry and Photobiology 91 (5): 1064-1070.

51. Zhang Y, Gao J, Chen Z (2019) A solid-state chemical reduction approach to synthesize graphitic carbon nitride with tunable nitrogen defects for efficient visible-light photocatalytic hydrogen 
evolution. Journal of Colloid and Interface Science 535: 331-340.

52. Zhang $Y$, Wang $M$, Yang G, Qi Y, Chai T, Li S (2018) Novel binary of $g-C_{3} N_{4}$ coupling and Eu ${ }^{3+}$ doping co-modifying bidirectional dendritic $\mathrm{BiVO}_{4}$ heterojunctions with enhanced visible-light photocatalytic performance. Separation and Purification Technology 202: 335-344.

53. Zhou J, Jiang L, Chen D, Liang J, Qin L, Bai L, et al. (2019) Facile synthesis of Er-doped $\mathrm{BiFeO}_{3}$ nanoparticles for enhanced visible light photocatalytic degradation of tetracycline hydrochloride. Journal of Sol-Gel Science and Technology 90 (3): 535-546.

54. Zhu X, Zhang J, Liu J, Zhang Y (2019) Recent Progress of Rare-Earth Doped Upconversion Nanoparticles: Synthesis, Optimization, and Applications. Advanced Science 6 (22): 1901358.

55. Zou Z, Wu T, Lu H, Tu Y, Zhao S, Xie S (2018) Structure, luminescence and temperature sensing in rare earth doped glass ceramics containing $\mathrm{NaY}\left(\mathrm{WO}_{4}\right)_{2}$ nanocrystals. RSC advances 8 (14): 76797686.

\section{Tables}

Table.1. The AL, SR and SGI with different infusion solution.

\begin{tabular}{|llll|}
\hline Samples & $\mathrm{AL}(\mathrm{mm})$ & $\mathrm{SR}(\%)$ & $\mathrm{SGI}$ \\
\hline DW & 27.5 & 95 & 1 \\
\hline CN & 28.7 & 90 & 0.989 \\
\hline 0.005TCN & 27.7 & 92 & 0.975 \\
\hline 0.01TCN & 27.3 & 92 & 0.961 \\
\hline 0.02TCN & 27.9 & 95 & 1.014 \\
\hline
\end{tabular}

\section{Figures}




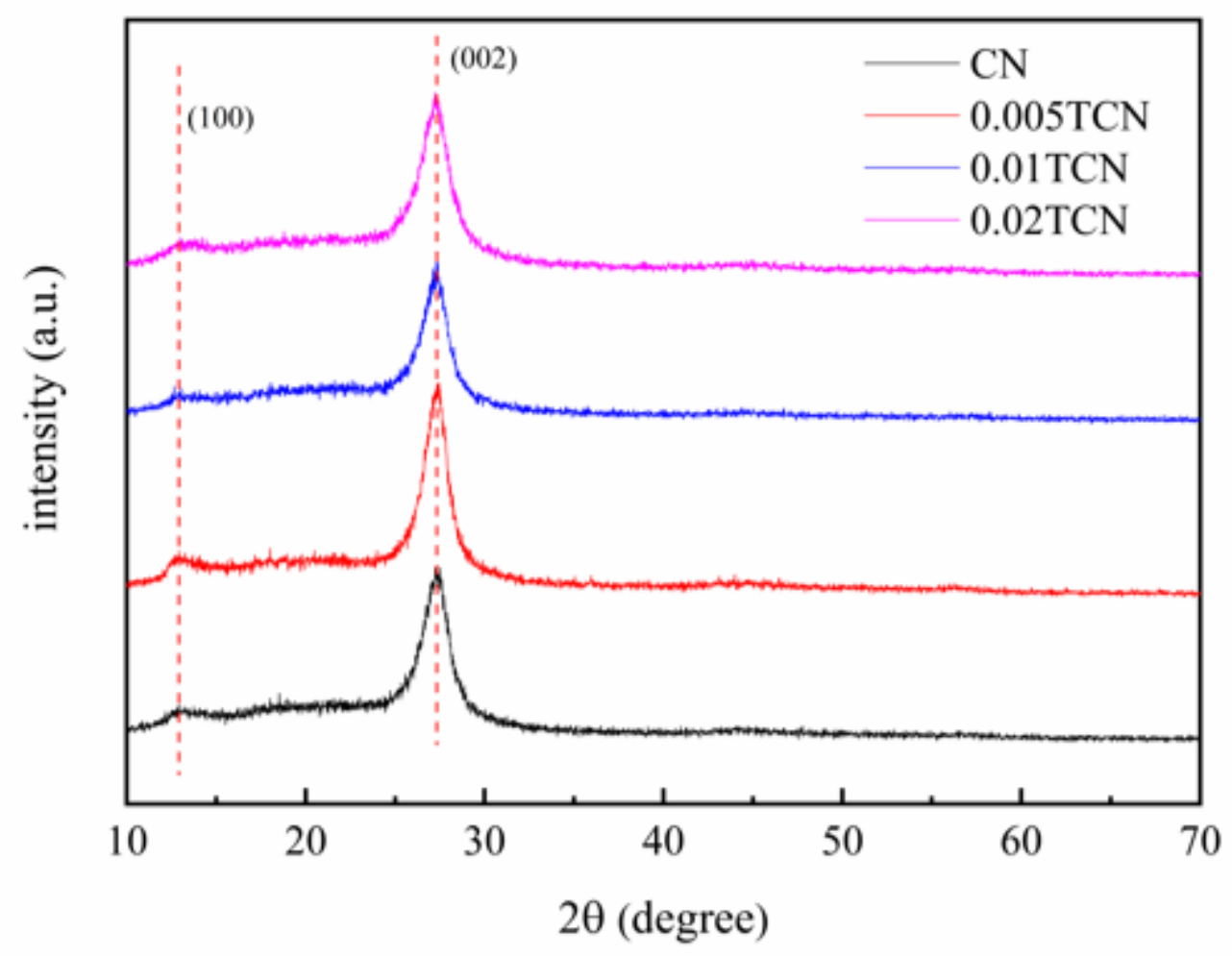

Figure 1

XRD patterns of $\mathrm{CN}, 0.005 \mathrm{TCN}, 0.01 \mathrm{TCN}$ and $0.02 \mathrm{TCN}$

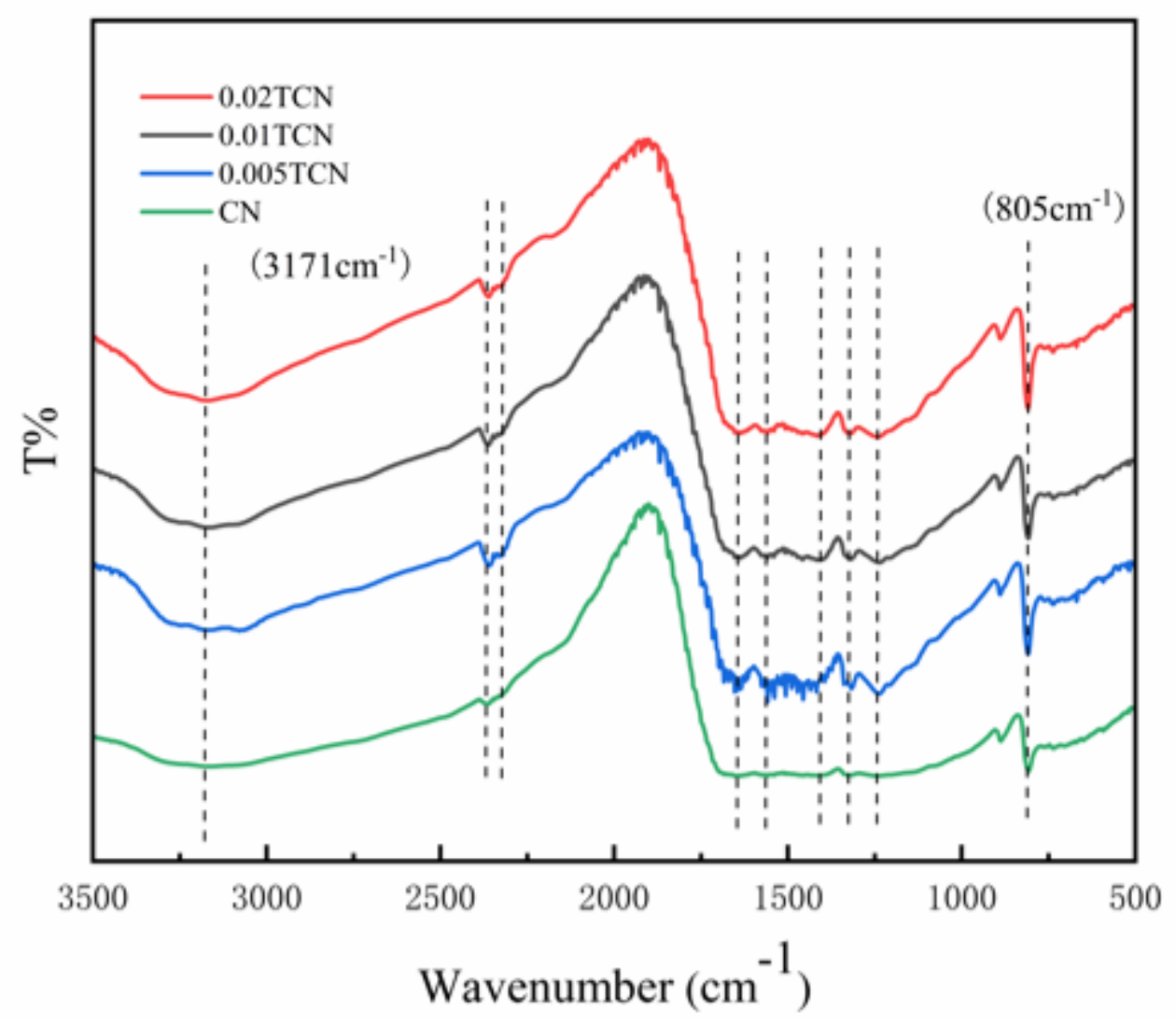

Figure 2 
FT-IR spectra of CN, 0.005TCN, 0.01TCN and 0.02TCN
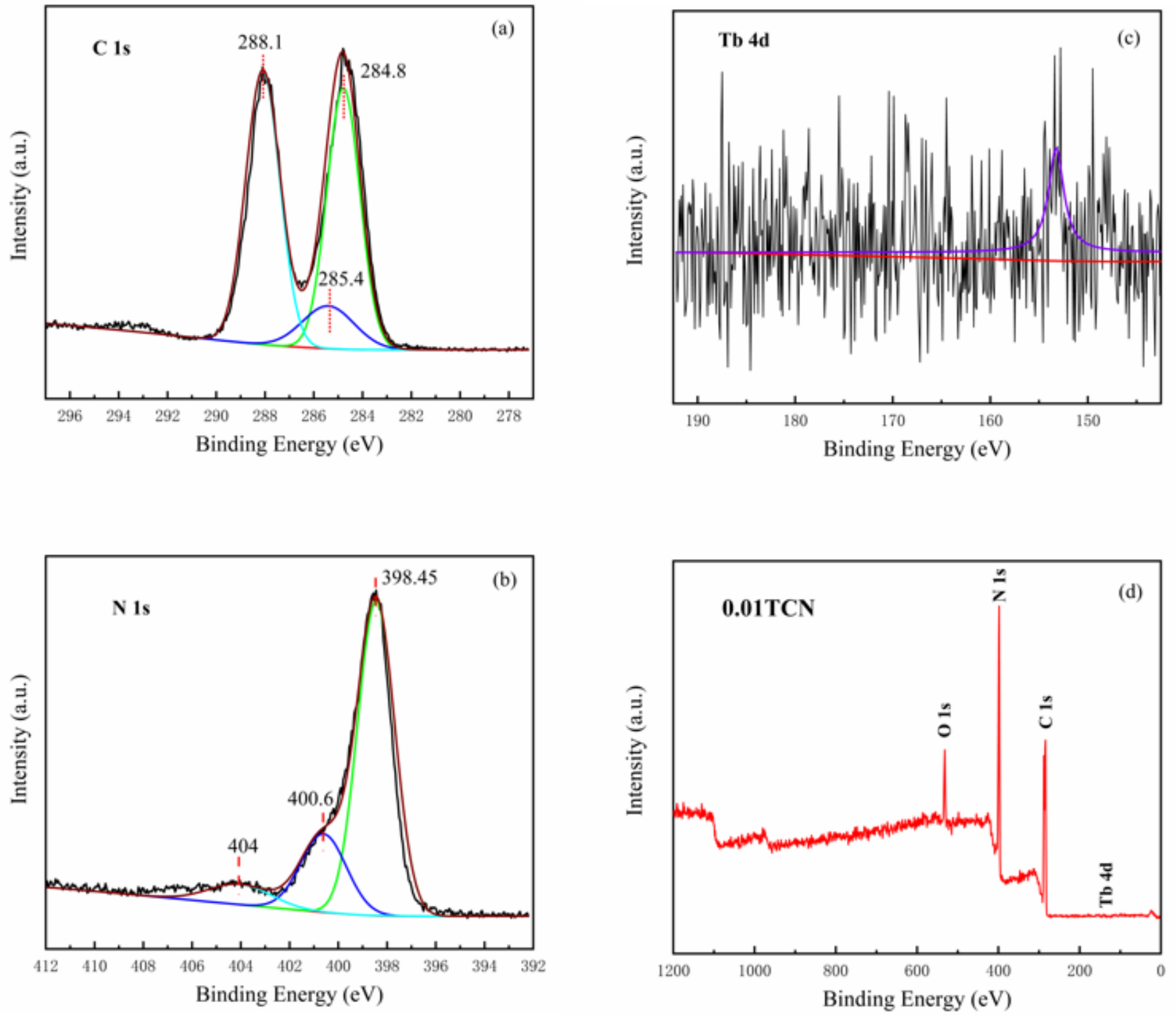

Figure 3

XPS spectra of C1s (a), N1s (b), Tb4d (c) and Tb/g-C3N4(d) 

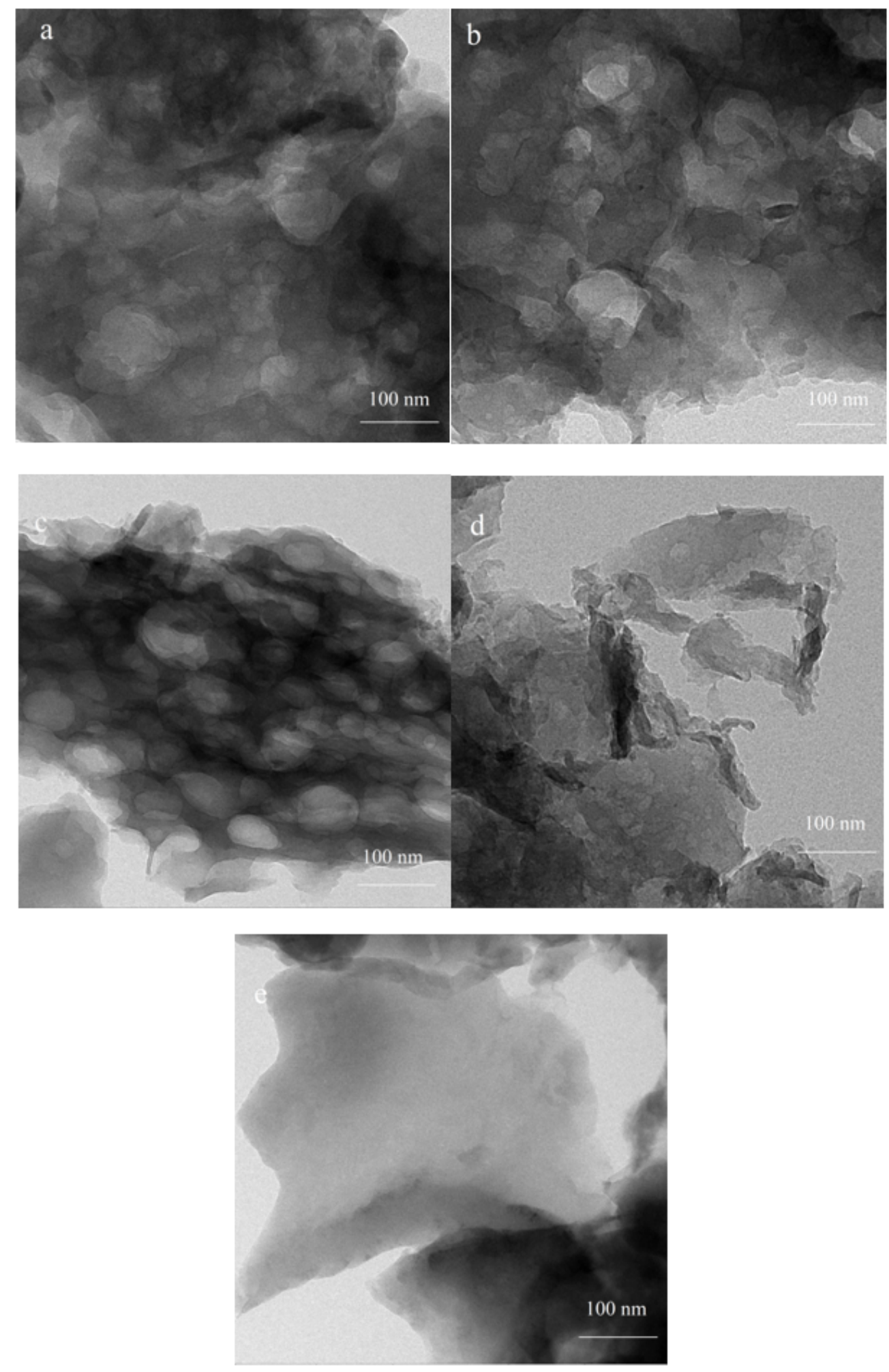

Figure 4

TEM images of $0.005 \mathrm{TCN}(\mathrm{a}), 0.01 \mathrm{TCN}(\mathrm{b}), 0.02 \mathrm{TCN}(\mathrm{c}), \mathrm{HCN}(\mathrm{d})$ and g-C3N4 (e) 


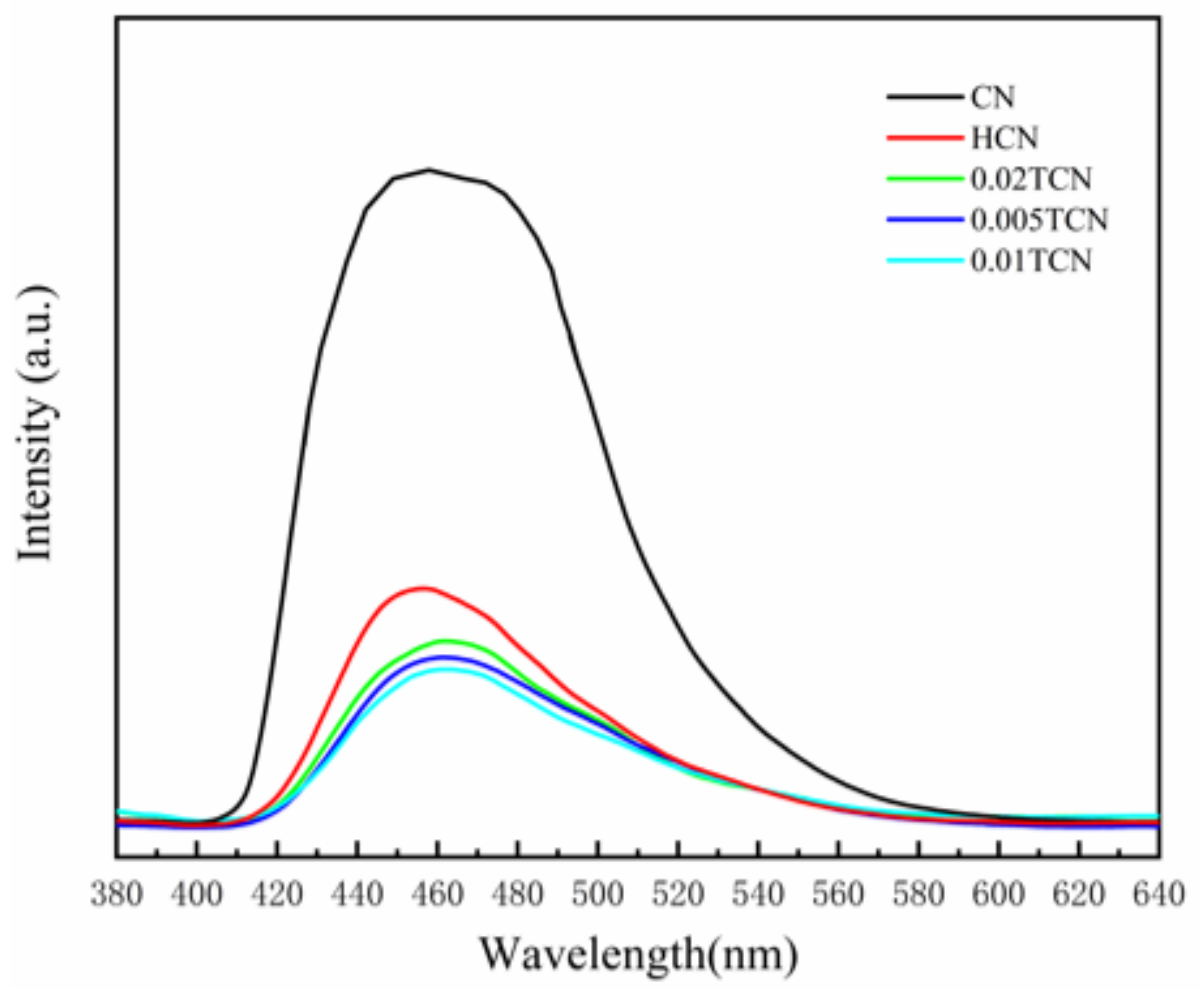

Figure 5

Photoluminescence spectra of g-C3N4, 0.005TCN, 0.01TCN, 0.02TCN and HCN

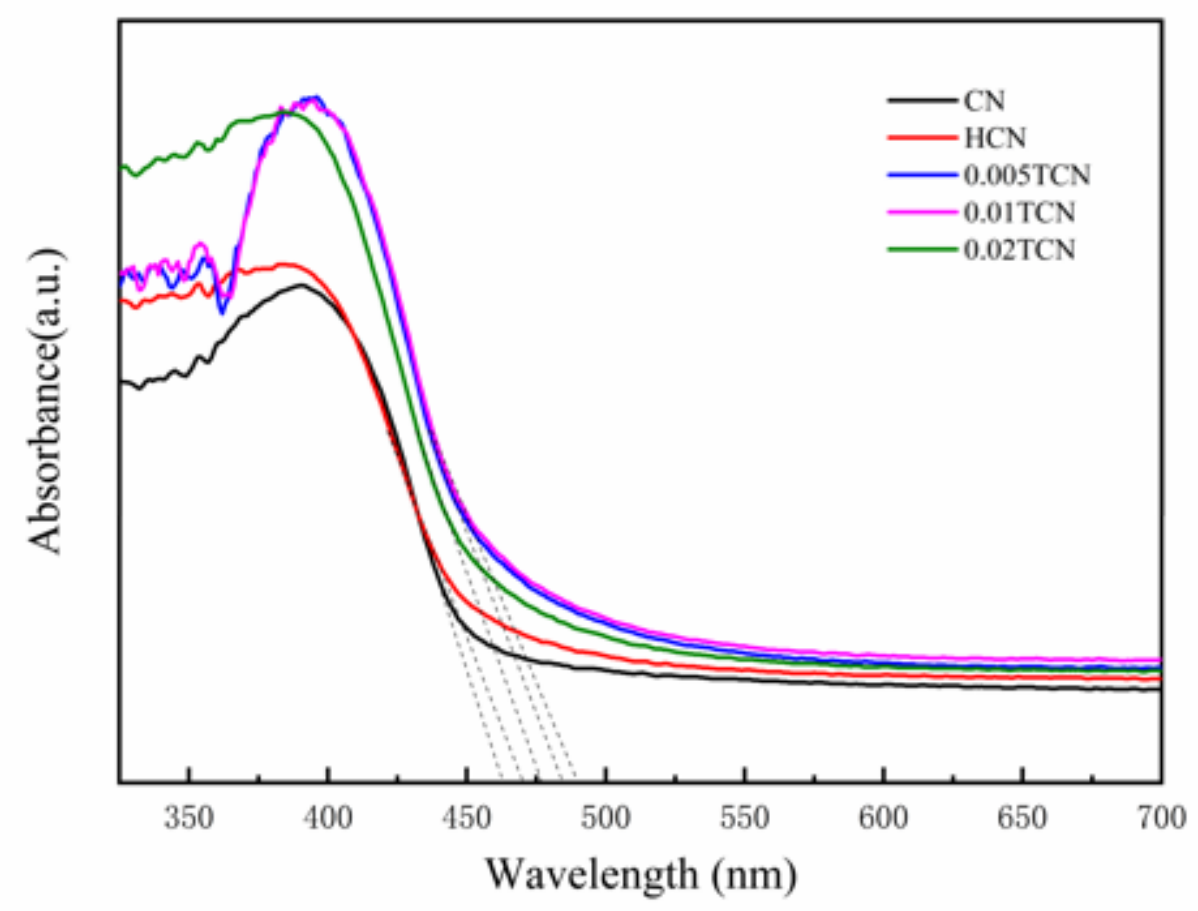

Figure 6

UV-Vis DRS spectra of TCN and CN 

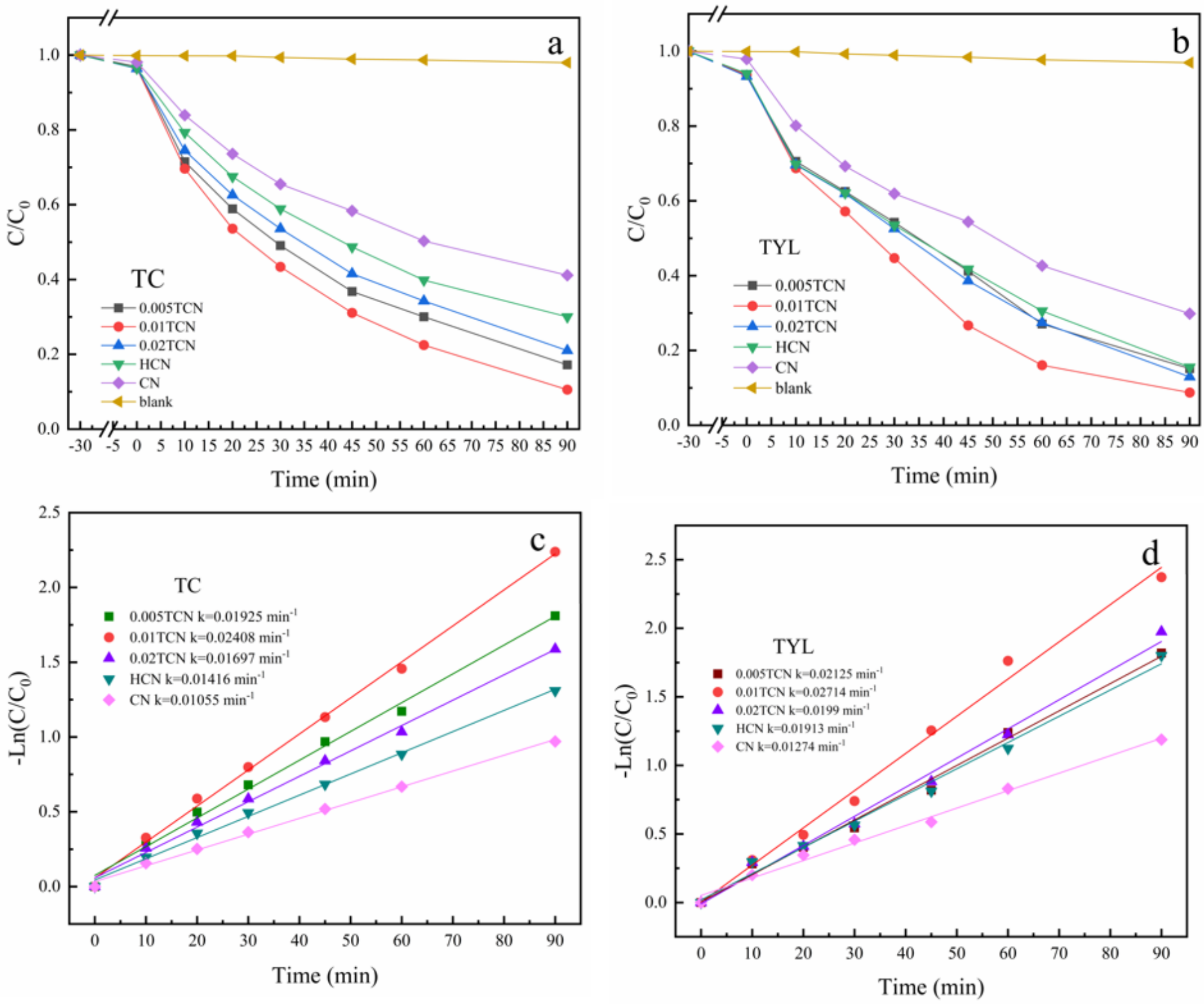

Figure 7

Comparison of photocatalytic activities of different samples for the degradation of TC (a) and TYL (b) solution; The pseudo-first-order kinetics curves of TC (c) and TYL (d) degradation over the different samples 


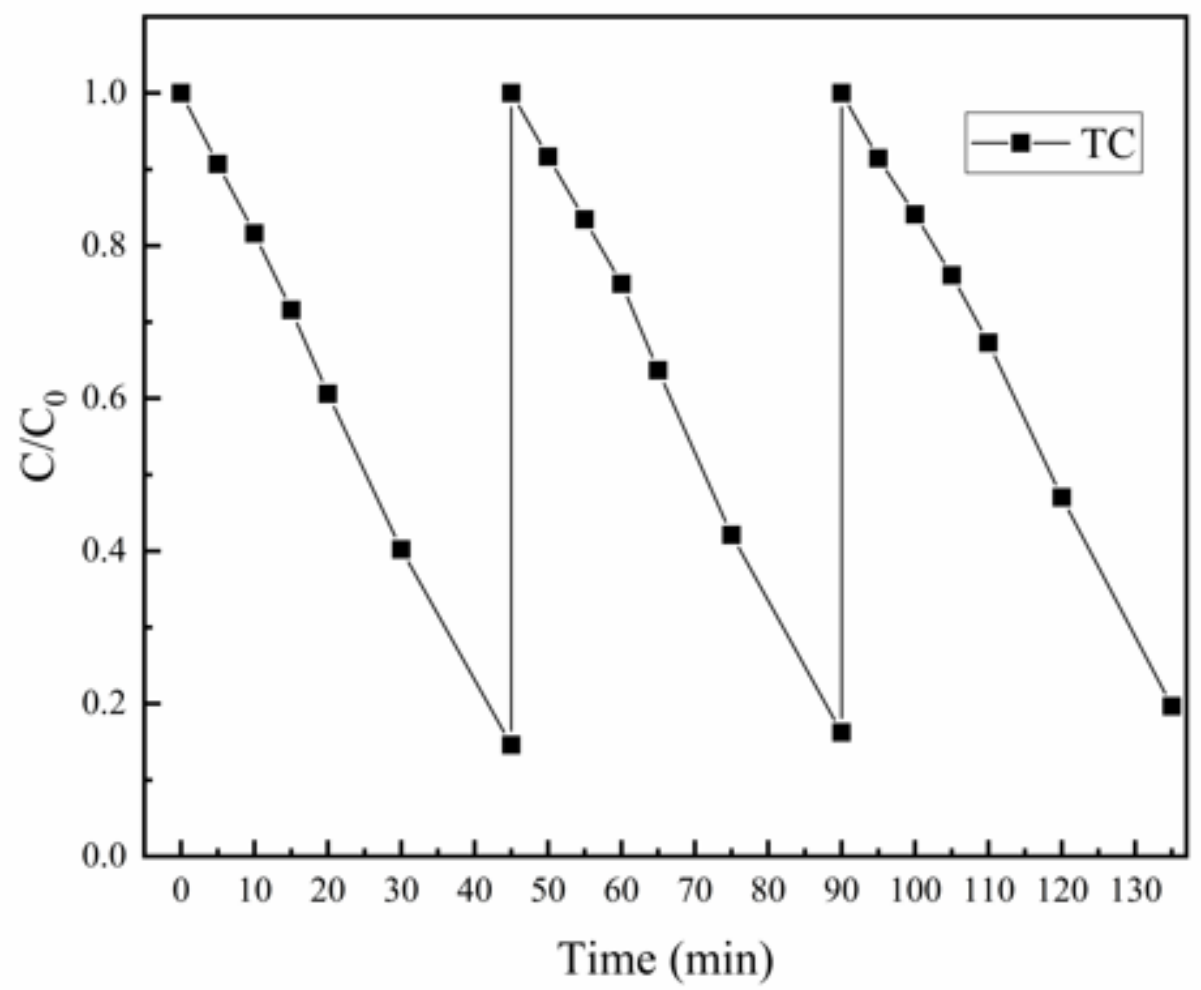

Figure 8

Cycling runs for the photocatalytic degradation of TC over 0.01TCN sample under simulated solar irradiation 

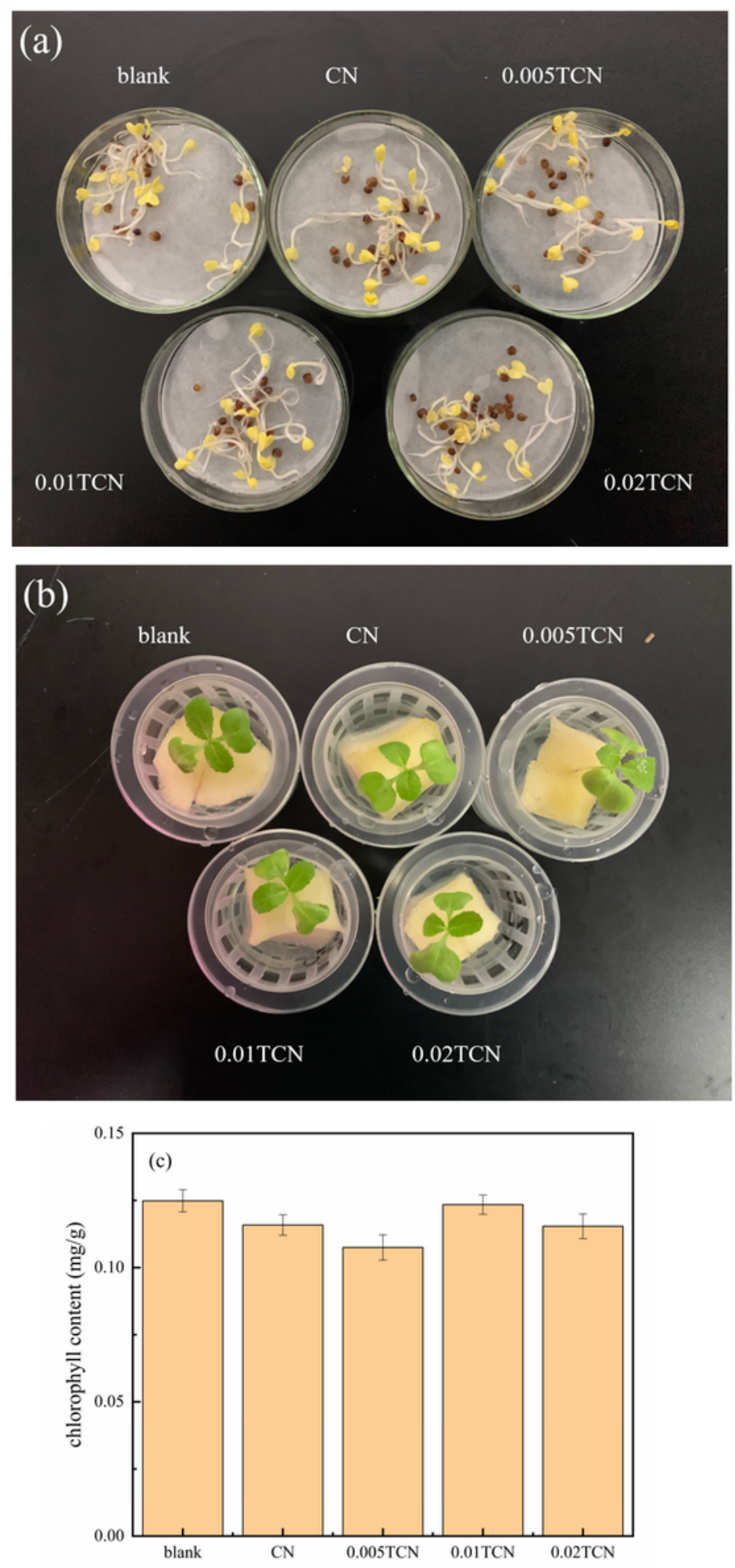

Figure 9

(a)Seed germination photos of different leaches; (b)Photos of seedling growth of Chinese cabbage with different leaching solutions; (c)The chlorophyll content of Chinese cabbage seedlings cultured in different leaching solutions 

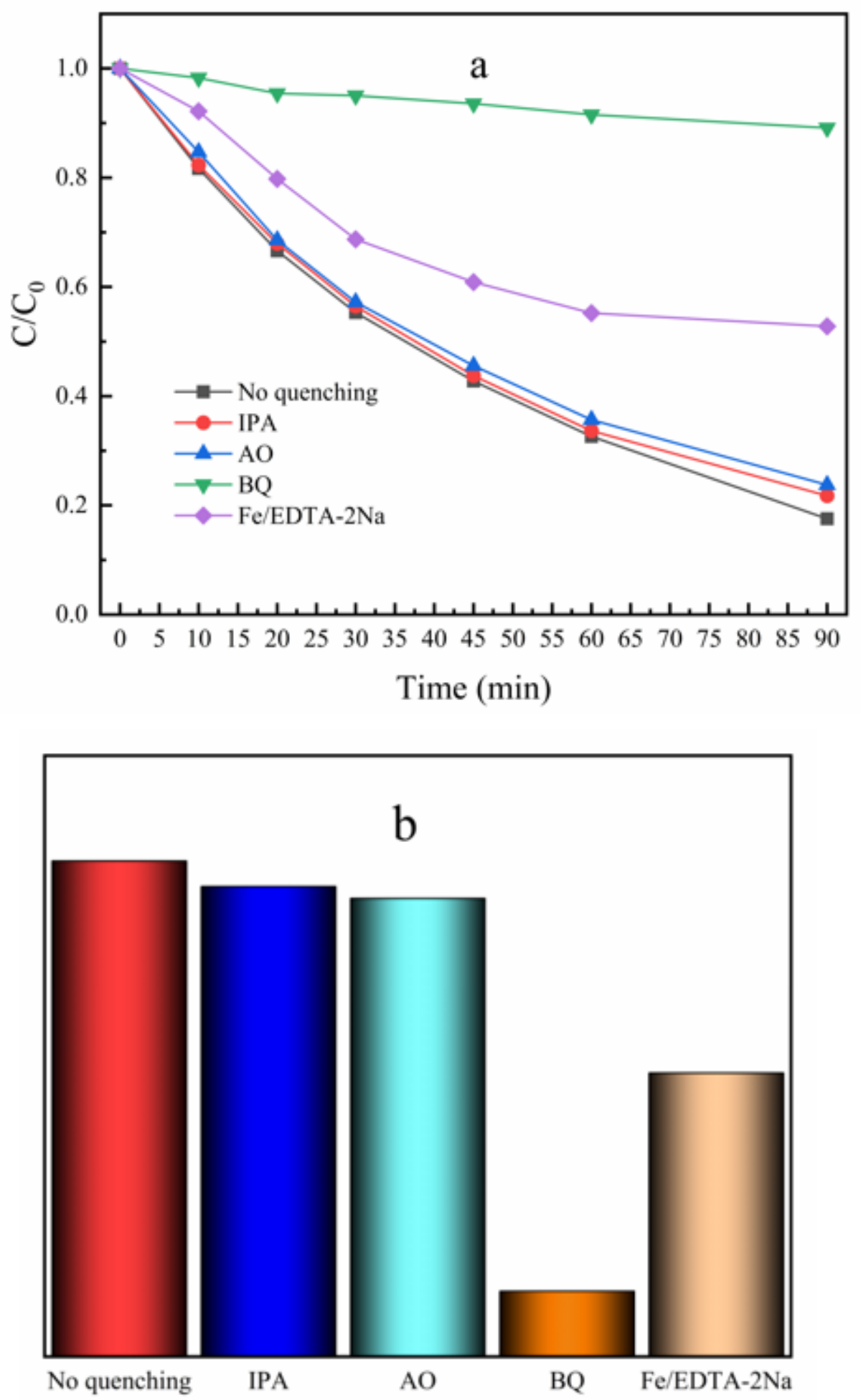

Figure 10

Effect of several scavengers on the photocatalytic activity of $0.01 \mathrm{TCN}$ (a) catalyst; The value of the removal rate in the presence of as-prepared $0.01 \mathrm{TCN}$ (b) sample 


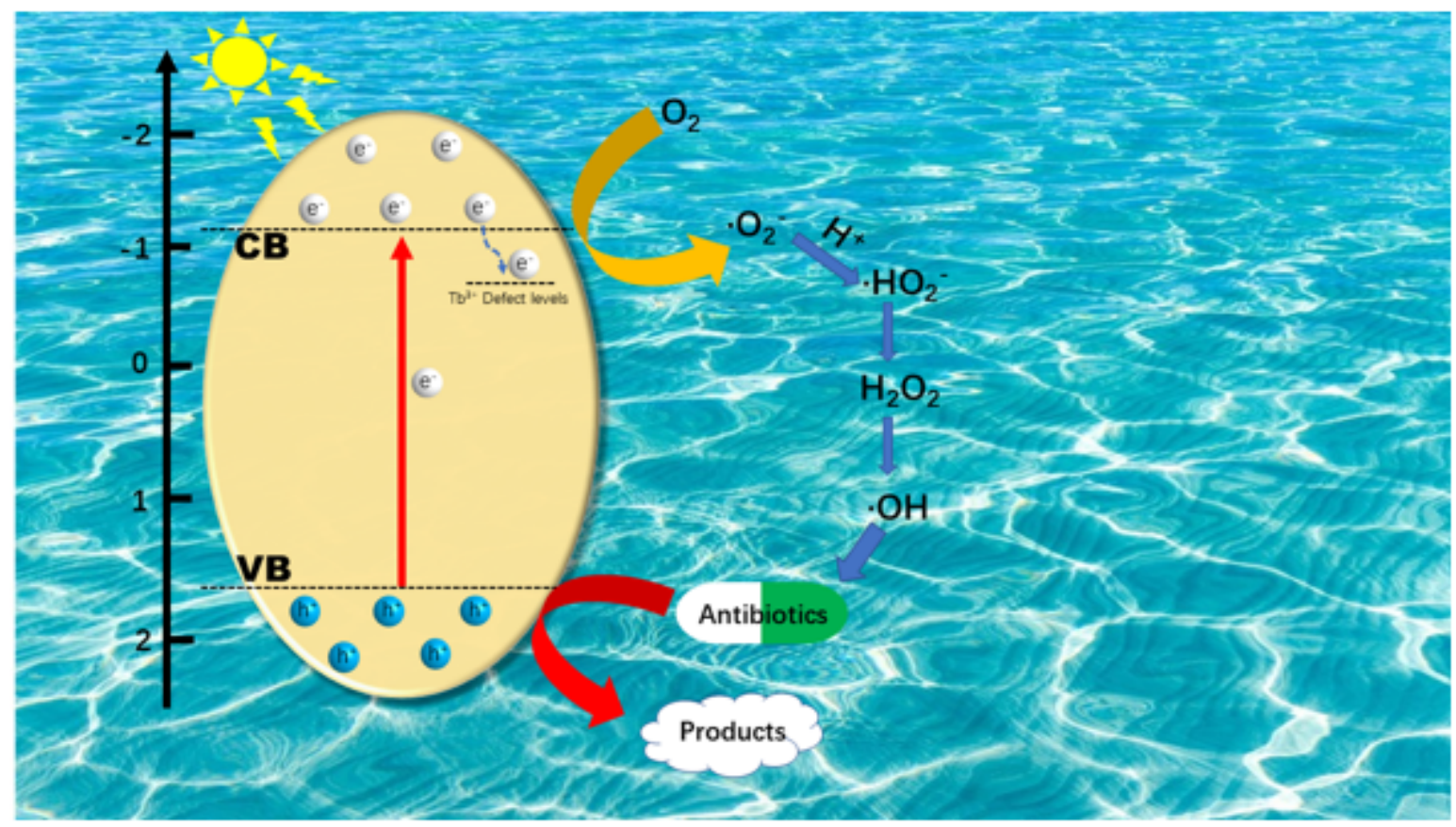

\section{Figure 11}

Schematic diagram of photocatalytic mechanism of Tb doped g-C3N4 photocatalysts 